Revista de Derecho YACHAQ N. ${ }^{\circ} 12$

Centro de Investigación de los Estudiantes de Derecho (CIED)

Universidad Nacional de San Antonio Abad del Cusco

ISSN: 2707-1197 (en linea)

ISSN: 1817-597X (impresa)

Fecha de recepción: 24/10/2020

Fecha de aceptación: 08/01/2021

[pp. 163-175]

\title{
Estado y Fe: a propósito de la propuesta legislativa del «Día Nacional de la Oración» y los días de ayuno y oración en la ciudad de Tumbes
}

\author{
State \& Faith: a perspective of «National Prayer Day» \\ bill and City of Tumbes' Fast and Pray Days
}

José Alfonso Lip Zegarra ${ }^{[*]}$

\begin{abstract}
Resumen: el presente trabajo tiene como objetivo analizar una norma jurídica y una propuesta de ley a la luz del derecho de libertad religiosa y los principios del Derecho Eclesiástico peruano, y la conveniencia o no de su existencia para el modelo de relaciones Iglesia - Estado consagrado en el Perú. Para lograr dicha finalidad, se ha estructurado el trabajo de la siguiente manera: en primer lugar, se definirán y enmarcarán los ámbitos y las dimensiones del derecho de libertad religiosa y los principios del Derecho Eclesiástico que los soportan. Posteriormente, se analizarán ambos documentos jurídicos, haciendo énfasis en la afectación del marco jurídico del modelo de relaciones peruano. A continuación, se presentará un panorama de las relaciones Iglesia - Estado en el Perú, para luego absolver la cuestión de la constitucionalidad de los instrumentos jurídicos analizados. Finalmente, se plantearán soluciones legales procesales frente a estas normas, a la par que exponer una reflexión final.
\end{abstract}

\begin{abstract}
: this paper aims to present an analysis of a law and a bill using religious freedom right and the principles of Peruvian Ecclesiastical Law as interpretation tools, as well as determine the convenience of its existence for the Peruvian State-Church relationship model. For achieving this objective, this paper will first define and frame religious freedom and Peruvian Ecclesiastical Law principles' scopes and dimensions. Next, we will proceed with the analysis of both legal documents, focusing on the Peruvian StateChurch relationship legal framework's affectations. Later, a panorama of Peruvian State -Church relationship will be presented in order to resolve about the constitutionality of
\end{abstract}

[*] Abogado por la Universidad de Piura y bachiller en Artes Liberales con Mención en Historia por la misma Casa de Estudios. Egresado de la Maestría en Derecho de la Empresa de la Universidad de Piura. Actualmente se desempeña como Abogado en temas procesales y corporativos en Estudio Cárcamo Abogados. Correo de contacto: alfonsolipz@gmail.com. 
those legal documents. Finally, legal procedures solutions for this case will be presented, along with our final thoughts of this matter.

Palabras Clave: día Nacional de la Oración, Derecho Eclesiástico, Modelo de Relación Iglesia-Estado, Derecho de libertad religiosa.

Key Words: national Prayer Day, Ecclesiastical Law, Church-State relationship model, religious freedom.

\section{INTRODUCCIÓN}

Con fecha 24.03.2020, el congresista Orestes Pompeyo Sánchez Luis, del Grupo Parlamentario «Podemos Perú», presentó un Proyecto de Ley, signado con el N.․ 4879/2020-CR, con la sumilla «Ley que declara el Día Nacional de la Oración», Proyecto que en su Artículo $2^{\circ}$ busca declarar como tal día al tercer domingo del mes de abril de cada año. Asimismo, el Gobierno Regional de Tumbes, mediante Ordenanza Regional N.ㅇ 005-2020/GOB.REG.TUMBESCR-CD de fecha 27.03.2020, ha declarado los días 28 y 29 de marzo de cada año en su región como «días de ayuno y oración por la salud de la población tumbesina». Mucho más allá de las buenas intenciones de los representantes de estos poderes del Estado, ¿es esto legal $-\mathrm{y}$ necesario- en un Ordenamiento jurídico como el peruano? En este artículo se intentará dar una respuesta a este presente y potencial panorama legal, a la luz del derecho de libertad religiosa y los principios del Derecho Eclesiástico del Estado, máximas que sirven como pautas de interpretación y que dotan de sentido y de unidad a esta rama del Derecho Público.

\section{PAPEL DE LA LIBERTAD RELIGIOSA EN EL ES- TADO CONSTITUCIONAL}

En primer lugar, conviene definir el derecho de libertad religiosa, del cual Susana Mosquera (2005), sostiene que:

«Comporta el derecho fundamental de todo individuo de formar parte de una determinada confesión religiosa, de creer en el dogma y la doctrina propuesta por dicha confesión, de manifestar pública y privadamente las consecuentes convicciones religiosas y de practicar el culto", precisando además que, como todo derecho de libertad, este tiene una vertiente negativa, la cual «garantiza la libertad de cada persona para decidir en conciencia que no desea tomar parte en actos de la naturaleza antes descrita» (p. 147).

Por otro lado, la Corte Constitucional de la República de Colombia, en su sentencia T-322/04, señala que la libertad religiosa comprende, entre otros:

(i) la libertad de profesar cualquier creencia religiosa libremente escogida, (que implica la libertad de información y de expresión sin las cuales la persona no podría formarse una opinión ni expresarla); (ii) la libertad de cambiar de religión y (iii) de no profesar ninguna, entre otras conductas que, no obstante pertenecer el individuo a una religión o confesión religiosas, deben ser respetadas por encima de cualquier propósito de coacción; (...) la posibilidad de (iv) practicarlas sin perturbación o coacción externa, contraria a las propias convicciones y (v) de realizar actos de oración y de cultos (...) (xi) determinar, de conformidad con la propia convicción, la educación de los hijos menores o la de los incapaces bajo su dependencia. (Corte Constitucional de la República de Colombia, SCC. Exp. N. T-824803, 2004).

Además, el Tribunal Constitucional peruano, en su sentencia recaída en el Expediente N. 0 3283-2003-AA/TC, ha expresado en su fundamento 18 los atributos jurídicos que involucran el derecho de libertad religiosa:

i) Reconocimiento de la facultad de profesión de la creencia religiosa que libremente elija una persona; ii) reconocimiento de la 
facultad de abstención de profesión de toda creencia y culto religiosa; iii) reconocimiento de la facultad de cambiar de creencia religiosa y iv) reconocimiento de la facultad de declarar públicamente la vinculación con una creencia religiosa o de abstenerse de manifestar la pertenencia a alguna. Es decir, supone el atributo de informar, o no informar, sobre tal creencia a terceros. (Tribunal Constitucional, STC. Exp. N. 3283-2003AA/TC, 2004).

En otras palabras, este derecho de libertad confiere a la persona el total dominio sobre sus propias creencias, proscribe toda intervención externa en el propio sentir religioso y le autoriza a expresar su fe, si es que decide hacerlo, de la manera que estime conveniente, individual o colectivamente.

Hasta aquí, enunciados la definición doctrinal del derecho de libertad religiosa y los matices jurídicos del mismo reconocidos tanto a nivel latinoamericano como por el Supremo Intérprete de nuestra Constitución, considero necesario recordar cuál es el bien jurídico protegido detrás de este derecho. Al respecto, concuerdo con la doctora Susana Mosquera (2005), quien señala la vertiente individual del derecho de libertad religiosa «se plasma como una facultad de la persona humana, que deriva de su dignidad, protege una esfera de acción muy particular de la misma, su libertad de pensamiento en el terreno religioso, su libertad de creencias».

A mi juicio, lo que se busca proteger con el derecho de libertad religiosa es la vinculación (o la inexistencia de ella, en el caso de los agnósticos $o$ ateos) de una persona humana con una divinidad, independientemente de su denominación: Dios, Alá, Yahvé, Buda, entre otros. Esta vinculación, nacida en el ámbito íntimo de cada sujeto y posteriormente exteriorizado mediante símbolos o a través de un grupo de personas con las mismas creencias, tiene como objetivo enaltecer al ser humano, ayudarle a buscar la trascendencia a él mismo, a través del ejercicio individual o colectivo de ritos, dogmas y ministerios de su determinada afiliación religiosa. Es en este contexto en el que la persona humana procura para sí misma un bien, materializado en el ejercicio libre y voluntario (o no ejercicio) de la facultad de creer en «algo», con la firme certeza y convicción de que ese «algo» le ayudará a construirse como una mejor persona, a dar respuestas a algunas interrogantes existenciales de la vida misma, a buscar consuelo y comprensión mediante una visión particular de la existencia y el dolor, entre otras actividades y cuestiones; todo con el fin de comprenderse a sí mismo en esa dimensión de su vida y enaltecer su propio ser.

A continuación, es necesario recordar que la Constitución Política del Perú, en su Artículo $50^{\circ}$, establece que:

Dentro de un régimen de independencia y autonomía, el Estado reconoce a la Iglesia Católica como elemento importante en la formación histórica, cultural y moral del Perú, y le presta su colaboración. El Estado respeta otras confesiones y puede establecer formas de colaboración con ellas (1993).

Dentro de esta declaración del constituyente podemos encontrar enunciados los principios de independencia y autonomía y de colaboración o cooperación. Además, en los incisos 2 y 3 del artículo $2^{\circ}$ de la Carta Magna, podemos apreciar otros dos principios: libertad religiosa e igualdad y no discriminación ${ }^{[1]}$.

[1] Artículo $2^{\circ}$.- Derechos fundamentales de la persona: «Toda persona tiene derecho a: (...); 2. A la igualdad ante la ley. Nadie debe ser discriminado por motivo de origen, raza, sexo, idioma, religión, opinión, condición económica o de cualquier otra índole; 3 . A la libertad de conciencia y de religión, en forma individual o asociada. No hay persecución por razón de ideas o de creencias. No hay delito de opinión. El ejercicio público de todas las confesiones es libre, siempre que no ofenda la moral ni altere el orden público. 
De entre ellos, Luis Prieto Sanchís (1991), afirma sobre el principio de igualdad que este «a lo que obliga es a no establecer discriminaciones o, lo que es lo mismo, a que las distinciones normativas respondan a una cierta justificación o razonabilidad», quedando este principio vulnerado cuando «las creencias religiosas sean tomadas en consideración como base de una disciplina normativa que no guarde una relación de razonabilidad, adecuación y proporcionalidad con el hecho religioso alegado como fundamento de la regulación específica» (pp. 192, 195).

Este principio, en otras palabras, proscribe el trato diferenciado injustificado estatal en materia religiosa, sea este entre confesiones o entidades religiosas, o entre personas que tengan un credo y otras que no; prohibiendo además que el Estado pondere favorablemente una de estas situaciones o, en general, las expresiones de los atributos que componen el derecho de libertad religiosa.

Asimismo, se debe tomar en cuenta lo enunciado por el profesor Contreras Mazario (2009), cuando afirma que el principio de cooperación o colaboración es

«Una técnica instrumental no dirigida a realizar una valoración directa y positiva de los intereses religiosos o de lo religioso en cuanto tal, sino en la medida en que resulte preciso para el pleno y real disfrute y ejercicio del derecho de libertad de conciencia (...) el término cooperación, en su concepto negativo, no puede significar nunca la unión de las confesiones religiosas y los poderes públicos para la consecución de determinados fines y objetivos comunes (...)» (p. 746).

El Tribunal Constitucional peruano, a su vez, afirma sobre este principio que

El término «colaboración» que emplea la Constitución indica que nuestro modelo constitucional no responde ni a los sistemas de unión ni a los sistemas de separación absoluta entre el Estado y las confesiones.
La colaboración entre el Estado y las confesiones es un lugar de encuentro equidistante de la unión y la incomunicación entre ellos. (Tribunal Constitucional, STC. Exp. N.응 06111-2009-PA/TC, 2009).

En ese sentido, el principio de colaboración supone que entre las entidades religiosas y el Estado debe reconocerse una necesidad de trabajar en conjunto, para la realización de fines en común -como el bienestar de los miembros de su credo, que son ciudadanos del Estado- y para la concreción de derechos fundamentales, como la libertad religiosa. Sin embargo, la suma de estos esfuerzos no puede suponer nunca que el poder político o el religioso puedan inmiscuirse entre sí, lo que me lleva a afirmar la importancia del principio de independencia y autonomía o de incompetencia recíproca, por el cual se reconoce que tanto las entidades religiosas como el Estado poseen distintos campos de acción, y se encuentra prohibida la intervención en las esferas de competencia exclusiva de cada una de ellas.

Así, según la conjunción de estos principios, las formas de colaboración que cada Estado establezca con las confesiones religiosas no pueden ser invasivas, a tal punto que uno intervenga en las decisiones de orden interno del otro; y, por el contrario, asegura una esfera de independencia y autonomía en el ejercicio de las funciones propias de cada actor; es decir, ser incompetentes entre sí en sus propias materias.

Habiendo realizado hasta el momento un recuento panorámico del derecho de libertad religiosa y de los principios del Derecho Eclesiástico del Estado reconocidos en el Ordenamiento jurídico peruano, es momento de recurrir al análisis específico de la norma y el documento señalados al inicio de esta investigación.

Análisis del Proyecto de Ley N. ${ }^{\circ} 4879 / 2020-$ CR y de la Ordenanza Regional N. ${ }^{\circ}$ 005-2020/ GOB.REG.TUMBES-CR-CD 
Ahora bien, es oportunidad de analizar los dos casos en concreto, tanto el Proyecto de Ley N. $\mathrm{o}$ 4879/2020-CR como la Ordenanza Regional N. 005-2020/GOB.REG.TUMBES-CRCD. Antes de comenzar, es necesario evidenciar que, en ambos casos, se vulneran todos los principios del Derecho Eclesiástico peruano; haciendo especial énfasis en la trasgresión procurada con la Ordenanza Regional, ya que esta se encuentra publicada en el Diario Oficial «El Peruano»; y, tal como lo señala el iter procedimental de la aprobación y promulgación de leyes, esta disposición entró en vigencia el día siguiente de su publicación, el 28.03.2020, debido a que no se establecieron fechas distintas para el inicio de su vigencia.

La vulneración de esta Ordenanza es tal, que en su Artículo $2^{\circ}$ señala lo siguiente: «ENCOMENDAR a los Directores de UGEL de Departamento de Tumbes ordene a los Directores de las Instituciones Educativas Públicas y Privadas, realicen la difusión para el cumplimiento correspondiente de la presente Ordenanza Regional al interior de sus instituciones» (Ordenanza Regional N. 005-2020/GOB.REG. TUMBES-CR-CD, 2020), teniendo como única justificación una solicitud del presidente de la Asociación Cristiana de Pastores Evangélicos de Tumbes, quien pidió se declare ayuno y oración los días 28 y 29 de marzo «como medida de acercamiento a Dios». Considero que esta Ordenanza es inconstitucional, debido a que el Estado ha realizado una declaración positiva a favor de un hecho religioso — que a su vez es símbolo activo de religiosidad para la gran mayoría de confesiones religiosas existentescomo es la oración, en vez de mantener una actitud neutral frente a este hecho, tal como lo prescribe el principio de independencia y autonomía consagrado constitucionalmente; siendo especialmente grave disponer que se ordene a las instituciones educativas públicas y privadas que acaten «el ayuno y la oración», inmiscuyéndose y vulnerando el derecho a la libertad religiosa de profesores y alumnos obligándolos a tomar parte de un rito activo de determinada religión, que podrían profesar o no; y aunque lo hicieran, constriñéndolos a realizar en un determinado momento y espacio actos de su fe, siendo que la profesión de la misma, es libre en lugar y tiempo y se encuentra sujeta a las reglas que cada entidad religiosa libremente estipule en su ámbito interno.

Sobre el Proyecto de Ley N. 4879/2020$\mathrm{CR}$, se debe acotar que, aunque no ha sido aprobado, es potencialmente una norma con rango legal, la misma que vinculará a los sujetos comprendidos en su alcance, que son toda la sociedad peruana y las autoridades militares y civiles (a quienes también generará obligaciones), tal como lo señalan los Artículos $2^{\circ}$ y $3^{\circ}$ del Proyecto ${ }^{2]}$.

Ahora, al analizar la exposición de motivos del Proyecto de Ley que declara el Día Nacional de la Oración se puede concluir que no se encuentra ninguna justificación objetiva que sustente la dación de tal norma, o alguna razón suficiente que valide la posible existencia de esta Ley, limitándose el autor del Proyecto a narrar la historia del nacimiento del Día de la Oración y señalar en qué países se celebra, precisando que en Estados Unidos y en Guatemala existen decretos que declaran este día como fiesta nacional, pero en los demás

[2] Artículo $2^{\circ}$.- Declaratoria: «Declárese el tercer domingo del mes de abril de cada año, como 'El Día Nacional de la Oración', la cual deberá ser celebrado (sic) como un día de clamor a Dios para bendecir a nuestra nación, nuestras autoridades civiles, militares y la familia que es la organización más importante de nuestra sociedad".

Artículo $3^{\circ}$.- De las coordinaciones interinstitucionales: «Las autoridades militares y civiles deberán dar el respaldo a las instituciones, organizaciones religiosas y la organización civil que realicen diversas actividades como caminatas y celebraciones en todo el territorio nacional en espacios públicos y privados habilitados para promover la unidad en la oración». 
países enumerados esta fecha se festeja no como una celebración estatal, sino como una expresión de fe de distintas Iglesias, como la Católica, la Bautista, el Ejército de Salvación, los Luteranos, los Metodistas, los Reformados, entre otras. Asimismo, la exposición de motivos señala la existencia del Acuerdo Nacional y la obligación de alcanzar el bienestar de la persona; lo cual es correcto, pero se debe de buscar el bienestar general de los ciudadanos, y no solo de un grupo particular en concreto. Finalmente, esta exposición señala que el Perú «es un país con una población mayoritariamente religiosa, con tradiciones y con una cultura que guarda conexión directa con la religión» y que la República del Perú «ha diseñado un sistema de relación con las entidades religiosas, establecido en la Constitución de la República, que se ha ido desarrollando progresivamente a través de la jurisprudencia constitucional, la ley y reglamento de libertad religiosa y otras normas de menor rango". Efectivamente, el modelo de relación Iglesia-Estado garantizado por nuestra Constitución es uno de índole colaboracionista, pero lo que el legislador ponente de la norma olvida es que el Tribunal Constitucional en el fundamento 19 de la sentencia recaída en el Expediente $\mathrm{N}$. ㅇ 3283-2003-AA/ $\mathrm{TC}$, ha reconocido el principio de inmunidad de coacción, el cual es consistente en que:

Ninguna persona puede ser obligada a actuar en contra de sus creencias religiosas; es decir, que no podrá ser obligada o compelida jurídicamente a obrar de alguna manera opuesta a dichas convicciones. Tal exención alcanza al ateo o al agnóstico, que en modo alguno puede ser apremiado a participar en alguna forma de culto, o a comportarse en coincidencia con los ritos y prácticas derivados de un dogma religioso, o a prestar juramentos bajo dichas formas y convicciones. (Tribunal Constitucional, EXP. N.ㅇ 3283-2003-AA/TC).

A la par de lo anterior, debo hacer una aclaración llegados a este punto. En la gran mayoría de los estados en donde se celebra el
«Día Mundial/ Nacional de la Oración», esta festividad no se encuentra regulada en el Ordenamiento de dichos países, sino más bien es un festejo celebrado única y exclusivamente por los distintos movimientos religiosos; es decir, esta celebración no cuenta con reconocimiento oficial como fiesta nacional mediante norma o disposición alguna, contrario a lo que expresamente se propone para el Ordenamiento peruano. Además, de la verificación de lo dicho por el parlamentario expositor del Proyecto de Ley, solamente se ha podido confirmar la presencia del «Día Nacional de la Oración» en los Estados Unidos de América, cuya norma data de mediados del siglo XX con antecedentes de fines del siglo XVIII, por lo que ya es parte del imaginario y las costumbres estadounidenses, siendo este día tolerado por el modelo de relaciones Iglesia-Estado que ese país posee.

Dicho lo anterior, es posible concluir que el ejercicio del «Día Mundial de la Oración» es la concreción del derecho de libertad de asociación que, aunque estrechamente ligado al derecho de libertad religiosa, es distinto: así, el primero confiere a los ciudadanos la potestad de agruparse organizadamente para realizar planes o conseguir objetivos colectivos de distinto tipo: altruista (comités, fundaciones), económicos (las distintas formas societarias reconocidas en la Ley General de Sociedades), culturales (asociaciones), entre otros. Por otro lado, el derecho de libertad religiosa, en su matiz colectivo, permite que los ciudadanos, organizados por una fe o creencia en común, puedan exteriorizarlas a la sociedad, y realizar las actividades necesarias con el objetivo de alcanzar sus fines. Así, el derecho de libertad religiosa -y los principios que lo soportan- se encuentra más ligado al desarrollo de la confesión misma y a las posibilidades y garantías que el Estado le pueda otorgar para su debido desarrollo en la sociedad que la contiene; mientras que el derecho de asociación protege la libertad de los ciudadanos de reunirse estructuradamente para poder conseguir un fin, como puede ser uno espiritual o de propa- 
ganda de su fe. En otras palabras, el «Día Mundial de la Oración» se encuentra plenamente amparado por el derecho de libertad de asociación; no siendo propiamente una manifestación del derecho de libertad religiosa, por lo que su inclusión en el Ordenamiento jurídico peruano utilizando este derecho como argumento se presenta como un agente extraño que, como concluiré más adelante, debe ser expulsado del sistema.

Entonces, cabe preguntarse si en virtud de esta norma se puede obligar a una persona a orar, a que le pida a Dios bendecir a la $\mathrm{Na}$ ción. ¿Y si es un Testigo de Jehová, quien no presta juramento a la bandera ni ante alguna autoridad, se le puede conminar a orar por las autoridades militares? ¿Cambiaría la respuesta si el sujeto obligado fuese agnóstico, ateo o musulmán, cuya presencia aún es incipiente en Perú? $O$ en el caso de que el sujeto obligado sea cristiano, ipuede ser obligado a orar en un día y hora específica, aunque este sujeto no lo quiera, ya que practica su fe de una manera distinta? Todas estas interrogantes deben ser respondidas en forma negativa, en la medida que las expresiones de fe, aunque pueden ser individuales o colectivas, siempre serán personalísimas, propias de cada persona, según sus propias circunstancias. En este orden de ideas, este Proyecto de Ley vulnera el derecho de libertad religiosa y los principios de libertad religiosa y de colaboración o cooperación, este último debido a que el Estado está supliendo una declaración propia de las entidades religiosas, haciéndola suya y de obligatorio cumplimiento para la ciudadanía. Este Proyecto también vulnera el principio de igualdad, ya que está concediendo un trato diferenciado injustificado a favor de las religiones cristianas en desmedro de la población agnóstica, atea o de otras confesiones.

Una mención aparte merece el artículo $3^{\circ}$ de este Proyecto, que decreta la obligación de las autoridades civiles y militares de prestar respaldo a las organizaciones civiles y religiosas que realicen actividades en espacios públicos y privados, lo cual claramente vulnera el principio de independencia y autonomía, debido a que la potencial norma está disponiendo que la organización estatal use su logística y recursos al servicio de actividades de índole religiosa, las cuales en principio le pertenecen única y exclusivamente a las entidades religiosas, forzando al Estado a tomar parte activa de estos ritos «para promover la unidad en la oración». De esta manera, se puede apreciar que esta Propuesta de Ley es también inconstitucional, y que de ser aprobada $-y$ contrario a lo que cree el ponente de la misma- sí se vería gravemente afectado el modelo de las relaciones Iglesia-Estado, quedando vulnerados todos los principios que la rigen.

\section{EL MODELO IGLESIA-ESTADO EN EL PERÚ}

Llegados a este punto es necesario profundizar, aunque alguna idea he dado líneas arriba, sobre el modelo de las relaciones Iglesia-Estado que el Perú actualmente posee. Históricamente, nuestro país ha sido un Estado confesional, llegando a reconocer en varias Constituciones a la Iglesia Católica $-y$ al catolicismo- como religión oficial, y prohibiendo en algunos momentos la profesión de cualquier otra religión, como es el caso de la Constitución de 1860 , que en su artículo $4^{\circ}$ declara que «La Nación profesa la Religión Católica, Apostólica, Romana: el Estado la protege, y no permite el ejercicio público de otra alguna». A partir de la Constitución de 1979 se puede apreciar un cambio en la actitud del Estado frente al hecho religioso, flexibilizando su actitud ante las religiones distintas a la católica, estableciendo la posibilidad de colaborar con ellas, tal como lo prescribe el Artículo $86^{\circ}$ de esta Carta Magna:

«Dentro de un régimen de independencia y autonomía, el Estado reconoce a la Iglesia Católica como elemento importante en la formación histórica, cultural, moral del Perú. Le presta su colaboración. El Estado puede también establecer formas de colaboración con otras confesiones.» (Constitución Política del Perú, 1979). 
Es la Constitución de 1993 —en su artículo $50^{\circ}$ - la que consolida el modelo de la relación Iglesia-Estado: un modelo de cooperación que ofrece el Estado peruano a todas las entidades religiosas. Asimismo, debo hacer una salvedad con respecto a las maneras de establecer las formas de colaboración con las entidades religiosas, distinguiendo la colaboración con la Iglesia Católica y con las demás confesiones.

Así, las relaciones que mantiene el Estado peruano con la Iglesia Católica son llevadas a nivel supranacional, debido a que la Iglesia Católica se encuentra representada en la Santa Sede, la cual cuenta con personalidad jurídica internacional. En el caso concreto, el instrumento en el que se formalizaron los acuerdos y entendimientos entre los dos sujetos con personalidad internacional recibió el nombre de Acuerdo entre la República del Perú y la Santa Sede, suscrito el 19.06.1980; ratificado el 24.07.1980 y canjeados los Instrumentos Jurídicos de Ratificación del Acuerdo el 26.07.1980, surtiendo efectos jurídicos para el Perú desde ese día.

Dicho lo anterior, es necesario precisar que, como toda relación entre dos sujetos de Derecho Internacional Público, los mecanismos de solución de controversias, interpretación e implementación del Acuerdo deben ser aplicados y/o resueltos con base en el común entendimiento de las partes (como, por ejemplo, intercambiando notas diplomáticas), y a la luz de los principios del Derecho Internacional, como lo son el pacta sunt servanda, bona fide y el ius cogens.
En el otro extremo, todas las demás confesiones religiosas (cristianos no católicos, protestantes, musulmanes, entre otras), no tienen la misma capacidad jurídica internacional que posee la Iglesia Católica representada por la Santa Sede, por lo que sus relaciones con el Estado peruano son desarrolladas bajo el principio de soberanía estatal, siendo el poder político el encargado de establecer los procedimientos internos para que las entidades religiosas no católicas puedan acceder a alguna forma de colaboración prevista en la norma nacional, que en este caso es la Ley de Libertad Religiosa y su Reglamento, que en otra oportunidad hemos criticado ${ }^{[3]}$, y cuya redacción actual impide que las confesiones religiosas no católicas lleguen a colaborar, reiterando que las normas aplicables para la Iglesia Católica se encuentran contenidas en su Acuerdo y el desarrollo del mismo, sea las notas diplomáticas intercambiadas que sirven como guía de interpretación o el desarrollo nacional de algún punto del Acuerdo, como es el caso del Informe 076-2011-SUNAT/2B0000 de fecha 17.06.2011.

Se aprecia, indudablemente, la diferencia en los procedimientos y en el marco rector de las relaciones entre el Estado, la Iglesia Católica y las demás confesiones religiosas, por lo que puedo afirmar que de la revisión de toda la normativa eclesiástica competente a este asunto; es decir, las directrices aplicables a las entidades no católicas y el mismo Acuerdo entre la Santa Sede y la República del Perú, no existe disposición alguna que permita, promueva o prescriba la declaración de días festivos con motivos o fines religiosos como forma

[3] Sobre las críticas a estos dispositivos, sucintamente podemos señalar que el nuevo Reglamento de la Ley de Libertad Religiosa, mediante Decreto Supremo N.o 006-2016-JUS, de fecha 18.07.2016, suprimió totalmente el apartado sobre la regulación y los procedimientos que las entidades religiosas distintas a la católica han de realizar para alcanzar la firma de un Acuerdo de Colaboración con el Estado peruano, apartado que sí se encontraba en el antiguo Reglamento, aprobado por Decreto Supremo N. 010-2011-JUS. Para profundizar en esta crítica, se puede consultar a LIP, José, La tributación eclesiástica en el Perú y los principios constitucionales del Derecho Tributario Eclesiástico: ¿una reforma necesaria? en: DÍAZ, Lelia y VÍLCHEZ, Ronald (Coords.), VI Convención de Derecho Público, Palestra, Lima, 2019, pp. 496-498. 
o materialización de una voluntad de colaboración; máxime que sí se encuentran normas que favorecen a las entidades religiosas en otras materias, como en la tributación, el establecimiento de centros educativos de cualquier nivel, la presencia de las confesiones en el ámbito militar y penitenciario, el manejo del patrimonio cultural en manos de las confesiones religiosas, etc. Así, desde el punto de vista normativo eclesiástico estatal, y utilizando los métodos de interpretación normativa sociológica, teleológica y armonizadora, no se encuentra justificación para la promulgación de la Ordenanza Regional ni para la aprobación del Proyecto de Ley que declara el «Día Nacional de la Oración». Es el mismo modelo de relaciones Iglesia-Estado el que encuentra extrañas este tipo de disposiciones, siendo que estas son incompatibles con lo estipulado a nivel legal y constitucional.

\section{¿Existen razones suficientes para la consti- tucionalidad de estas normas?}

Después de este pequeño recuento sobre la situación de las entidades religiosas y su vinculación con el Estado peruano, podemos preguntarnos si la Ordenanza Regional N. 0 0052020/GOB.REG.TUMBES-CR-CD y el Proyecto de Ley N.o 4879/2020-CR son expresiones del «sistema de relación con las entidades religiosas», tal como lo menciona la exposición de motivos de este último. Aparentemente, la respuesta a esta interrogante podría ser positiva, debido a que esta normativa recoge el sentir de la mayoría de la población, sea en la Región Tumbes o en el Perú[ ${ }^{[4]}$, y es obligación estatal procurar las mejores condiciones para que los fieles puedan ejercer colectivamente su credo; pero lo cierto es que con la Ordenanza el Gobierno Regional de Tumbes ha tomado una posición favorable sobre el hecho religioso solicitado por el representante del credo evangé- lico de esa circunscripción. Al requerir que los directores de las Unidades de Gestión Educativa Local inspeccionen que todos los colegios públicos y privados cumplan con lo decretado, el Gobierno Regional de Tumbes, como parte del aparato estatal, da un paso más grave a la infracción no solo del derecho a la libertad religiosa, sino del derecho de los padres a educar y a participar del proceso educativo planteado para sus hijos, reconocido constitucionalmente en el artículo $13^{\circ}$ de nuestra Carta Magna, el mismo que señala que:

«La educación tiene como finalidad el desarrollo integral de la persona humana. El Estado reconoce y garantiza la libertad de enseñanza. Los padres de familia tienen el deber de educar a sus hijos y el derecho de escoger los centros de educación y de participar del proceso educativo». (1993).

Por todo lo que hasta ahora hemos reflexionado, resulta descabellado pensar que, usando como sustento esta Ordenanza, pueda obligarse a un niño o a un adolescente a rezar o a guardar ayuno, menos aún sancionar al menor o iniciar un procedimiento sancionador al profesor que no hace cumplir esta norma o al supervisor de la Unidad de Gestión Educativa que no observó que todos los menores en edad escolar guarden ayuno y oración. Además, queda la pregunta de cómo se debe hacer cumplir esta Ordenanza, es decir, sobre su implementación en el ámbito educativo: ¿se debe mandar una esquela a los padres -de instituciones públicas y privadas- conminándoles que a fin de pedir «por la salud de la población tumbesina» guarden ayuno? ¿Se deben modificar los reglamentos y/o los idearios de los colegios afectados por esta norma, o adecuar sus calendarios académicos anuales? ¿Tal vez requerir que los alumnos lleven a su Institución Educativa un rosario, una Torá o una alfombra de oración? Como puede apreciar, estimado

[4] Según el censo realizado por el Instituto Nacional de Información y Estadística (INEI), en el año 2017, 76 \% de los peruanos son católicos; $14.1 \%$ son evangélicos; 4.8 \% son de otro credo y $5.1 \%$ no tienen religión. 
lector, con cada opción propuesta se hace más irrisoria la situación sobre la posible aplicación de esta Ordenanza en el contexto de la Región Tumbes. Es por todo esto que reafirmo la inconstitucionalidad de esta Ordenanza y de los subsecuentes actos que sean dictados amparados en esta norma, toda vez que el sustento de la misma adolece de un vicio insubsanable, siendo solamente posible su reparación mediante la revisión de oficio que pueda realizar esta Administración pública, o por una impugnación judicial, a través de un proceso constitucional, del cual hablaremos en el apartado final de esta investigación.

Del mismo modo opina nuestro Tribunal Constitucional, en la sentencia recaída en el Expediente N.o 05680-2009-AA/TC, refiere específicamente para una fiesta propia de la Iglesia Católica - pero bien puede ampliarse hacia todos los credos- que el hecho que la religión sea un elemento importante en la formación del Perú y se busque una colaboración hacia la misma promovida desde el propio Estado:

«No justifica de ninguna manera que desde el ámbito de la administración pública se imponga la práctica de costumbres y ritos religiosos por más arraigados que estos resulten en el sentimiento mayoritario de la población (....). De allí que utilizar el vínculo institucional creado (...) lesione la libertad religiosa no solo de quienes no comulgan con la fe católica (sea por pertenecer a otros credos, sea por asumir posiciones abiertamente agnósticas), sino incluso la de aquellos que, pese a pertenecer a la religión católica, tampoco tienen por qué verse obligados a que el Estado les diga en qué momentos o circunstancias deben hacer suyas las prácticas de su propia religión». (Tribunal Constitucional, STC. Exp. N. 0 05680-2009-PA/TC, 2010).

En cuanto al Proyecto de Ley, la respuesta a la cuestión planteada puede también aparentemente ser positiva, debido a que el Estado tiene la obligación de poner al servicio de la mayoría de la ciudadanía toda su logística, con el fin de salvaguardar la integridad física de los fieles y su derecho al culto. Aunque este argumento pueda parecer de peso y ser lo suficientemente fuerte para soportar la existencia de la potencial Ley, lo cierto del asunto es que el Estado - tal como lo he venido explicandotiene un deber de neutralidad frente al hecho religioso, entendido este como a favor o en contra de una confesión en detrimento de otra o frente a la elección de no expresión del mismo. En otras palabras, es deber del Estado no tener una postura oficial a favor de una o varias confesiones, en detrimento de las demás y en menoscabo en aquellos ciudadanos que no profesan ninguna religión, cuyo número ha ido en ascenso en los últimos años. Es en este contexto que se presentan los principios del Derecho Eclesiástico, que sirven como guías de interpretación y máximas de actuación entre los sujetos vinculados a ellos, como lo son el Estado y las confesiones religiosas. Así, y llevando a efectos prácticos esta norma, cla autoridad policial y militar deberá calendarizar el «Día Nacional de la Oración» y esperar que todas las asociaciones civiles y religiosas soliciten resguardo para sus peregrinaciones o convenciones? Otra interrogante que surge es qué entidades religiosas pueden pedir este tipo de apoyo al Estado: ¿las confesiones inscritas en el Registro de Entidades Religiosas o las descritas en la exposición de motivos del Proyecto? ¿Podrían las sectas o entidades no registradas solicitar el apoyo de la autoridad? Los ateos y agnósticos organizados en una asociación civil, ¿pueden realizar clamores y rezos o pedir resguardo policial? ¿Cuántos agentes policiales y militares se asignarán a cada actividad? Y si se realiza la celebración en un espacio privado, pero que se encuentra en régimen de copropiedad, ¿puede la Policía Nacional del Perú ingresar sin el consentimiento de todos los copropietarios, simplemente debido a que esta norma los obliga a dar respaldo de seguridad o de cualquier otra clase? Una vez más, se evidencian las situaciones absurdas a las que lleva la norma propuesta 
por el congresista Sánchez Luis. Es claro que este Proyecto de Ley es mucho más que una simple norma declarativa que busca conceder un nombre a un día específico del calendario nacional, y más bien otorga un mandato a las autoridades militares y civiles, obligándolos a tomar parte en hechos y actividades netamente religiosas, lo cual no puede ser amparado por ninguna Ley.

Debemos agregar, además, que todas las intenciones, ideas y manifestaciones de un sentimiento ecuménico entre las entidades religiosas son un gran ejemplo de libertad y tolerancia religiosa, pero los mismos se corrompen y pierden su sentido cuando se busca la inclusión de los actos propios de estas dentro del ámbito estatal. La actividad ecuménica que las confesiones religiosas están desarrollando en estos últimos tiempos, como lo es el Consejo Interreligioso del Perú, es una oportunidad de promover el entendimiento religioso y de tender puentes comunes para asegurar el disfrute de la dimensión colectiva del derecho de libertad religiosa, pero estas actividades deben encontrarse dentro del marco de relaciones Iglesia-Estado consagrado por la República del Perú; marco que se encuentra definido por los principios del Derecho Eclesiástico reconocidos constitucionalmente.

Todo lo anteriormente argüido permite reafirmar que este Proyecto de Ley lesiona los principios de libertad religiosa, cooperación, igualdad y no discriminación, así como el principio de independencia y autonomía.

\section{REFLEXIONES FINALES Y A MANERA DE CON- CLUSIÓN}

Después de todos los comentarios vertidos hasta este momento, finalmente cabe realizar la pregunta: ¿qué recursos legales se pueden interponer ante estos dos documentos, habiendo quedado acreditada su inconstitucionalidad?; es decir, cuáles son las alternativas que brinda el Ordenamiento peruano a fin de expulsar normas inconstitucionales. En este punto es necesario dividir la respuesta según el documento jurídico analizado: con respecto al Proyecto de Ley N.․ 4879/2020-CR, al encontrarse actualmente en condición de propuesta, no procede ningún recurso por cuanto aún no es ley, pero en caso de ser aprobada y publicada, puede aplicarse las acciones legales previstas para el caso de la Ordenanza Regional N.o 005-2020/GOB.REG.TUMBES-CR-CD. Así, para esta última la garantía a interponer será la Acción de Inconstitucionalidad, recogida en el Artículo $200^{\circ}$ Inciso 4 de la Constitución, por la vulneración de los Artículos $2^{\circ}$ inciso 3 y $50^{\circ}$ de la misma; y en el caso de una afectación en particular, como lo es el obligar a un alumno a realizar oración y ayuno, o un procedimiento administrativo en contra de un docente utilizando como base el incumplimiento de la Ordenanza, procedería una Acción de Amparo por vulnerar el derecho de libertad religiosa, recogido en el Artículo $2^{\circ}$ inciso 3 de la Constitución Política del Perú. Recordemos que la acción de amparo se encuentra contemplada en el Artículo $200^{\circ}$ inciso 2 de la Constitución, y señala que «procede contra el hecho u omisión, por parte de cualquier autoridad, funcionario o persona, que vulnera o amenaza los demás derechos reconocidos por la Constitución. (...)», mientras que el inciso 4 contiene la acción de inconstitucionalidad, la misma que procede «contra las normas que tienen rango de ley: leyes, decretos legislativos, decretos de urgencia, tratados, reglamentos del Congreso, normas regionales de carácter general y ordenanzas municipales que contravengan la Constitución en la forma o en el fondo» (1993).

Es de hacer notar, además, la diferencia entre ambas garantías constitucionales, siendo que el efecto de la Acción de Inconstitucionalidad es expulsar la norma del Ordenamiento jurídico, con la consecuencia anexa que al día siguiente de su publicación en el Diario Oficial «El Peruano», la norma queda sin efecto, como lo señala el artículo $204^{\circ}$ de la Constitución; mientras que con la Acción de Amparo se busca la «restitución o restablecimiento del 
agraviado en el pleno goce de sus derechos constitucionales, ordenando que las cosas vuelvan al estado en que se encontraban antes de la violación», como se detalla en el artículo $57^{\circ}$ del Código Procesal Constitucional, en el apartado correspondiente al contenido de la sentencia fundada en un proceso de amparo. Es decir, se busca el cese del acto que vulnera el derecho fundamental de una persona en el caso concreto, como lo es el obligar a un ciudadano ateo o agnóstico a orar frente a un crucifijo o una estatua de un santo.

La libertad religiosa es uno de los derechos más necesarios que tenemos, ya que se encuentra íntimamente ligada a la libertad de conciencia y, en definitiva, al derecho a la igualdad entre ciudadanos, independientemente de su credo. Nadie puede ser perseguido por sus creencias religiosas, ni ser conminado a profesar o a realizar actos de fe de una religión, sea creyente de alguna o no. Asimismo, los ciudadanos tenemos el derecho a que nuestro Estado ocupe su tiempo y recursos en asuntos orientados a la obtención del bien común, y que este no intervenga en, ni sea intervenido por algún otro sujeto en asuntos de su exclusiva competencia.

Sin perjuicio de lo anteriormente señalado, es necesario reiterar el acierto que supone el promover movimientos ecuménicos y de entendimiento entre credos religiosos, pero estos no deben ser canalizados a través del Estado, que debe asumir una actitud neutral frente al desarrollo de las distintas manifestaciones religiosas. En ese sentido, considero como solución a esta situación inconstitucional que el Estado realice un estudio profundo de la evolución y la presencia de las distintas entidades religiosas en el territorio nacional, a fin de que pueda sincerar la legislación en materia eclesiástica vigente y que a futuro pueda dictar directrices y normas acordes con un modelo cooperacionista, o modificar las disposiciones existentes, para garantizar el pleno desarrollo del derecho de libertad religiosa en su matiz colectivo. Así, dentro del Ministerio de Justicia y Derechos Humanos se encuentra la Dirección General de Justicia y de Culto, que a su vez incluye a la Dirección de Asuntos Interconfesionales y a la Dirección de Asuntos Iglesia Católica, siendo estos órganos de la Administración pública los llamados a realizar un verdadero análisis de la situación de las confesiones religiosas en el Perú, y proponer la mejor manera de colaborar con las mismas sin que ello signifique vulnerar el principio constitucional de independencia y autonomía.

Además, considero como una solución alternativa a las acciones constitucionales detalladas supra respecto al problema que supone instaurar los «días de ayuno y oración por la salud de la población tumbesina» en las instituciones educativas públicas y privadas en la región Tumbes, la convocatoria a los padres de familia del alumnado — sea de manera global o de manera representativa a través de las Asociaciones de Padres de Familia (APAFAS) - para que de manera consensuada con los representantes de la Institución Educativa y/o los funcionarios de las Unidades de Gestión Educativa Locales puedan Ilegar a un acuerdo sobre la implementación de esta obligación legal en el plantel y los procedimientos para exonerarse del cumplimiento de la misma, garantizando de esta manera el derecho de los padres de familia de participar en la formación de sus hijos y el derecho de libertad religiosa de los menores de edad.

También es necesario agregar que cada Estado a nivel mundial tiene su propio modelo de relaciones Iglesia-Estado, sea un modelo como el de Estados Unidos, en donde priman las cláusulas de «non stablishment» y de «free excercise»; o estados con un modelo claramente confesional, como Costa Rica, Grecia o los países islámicos. El Perú ha optado por un modelo manifiestamente plural, de colaboración, de no desprecio a la dimensión colectiva del derecho de libertad religiosa, y es deber del Estado respetar la voluntad del constituyente como poder originario, cuya voluntad sobre los temas religiosos se encuentra plasmada en el Artículo $50^{\circ}$ de la Constitución. 
Las normas analizadas bajo los principios del Derecho Eclesiástico rompen con el marco de las relaciones, inclinando injustificadamente el poder público a favor de determinadas confesiones, desatendiendo los preceptos constitucionales de independencia, autonomía e igualdad de trato entre entidades religiosas y entre ciudadanos que profesan o no una fe. $Y$ es un escenario de vulneración sistemática real al derecho de libertad religiosa de la población de Tumbes; y en potencia, a todo el Perú, hecho manifiestamente inconstitucional.

\section{REFERENCIAS BIBLIOGRÁFICAS}

Contreras Mazario, J. (2009). La financiación «directa» de las minorías religiosas en España, en: Navarro; Mantecón y Martínez, (Coords.). (2009). La libertad religiosa y su regulación legal. Madrid: lustel.

Mosquera Monelos, S. (2005). El derecho de libertad de conciencia y de religión en el Ordenamiento jurídico peruano. Lima: Palestra.
Prieto Sanchís, L. (1991). Principios Constitucionales del Derecho Eclesiástico español, en: Iban, Prieto y Motilla. Curso de Derecho Eclesiástico. Madrid: Universidad Complutense de Madrid.

\section{REFERENCIAS JURÍDICAS}

Constitución Política del Perú (1993). Diario Oficial El Peruano.

Ley que declara el Día Nacional de la Oración. Proyecto de Ley N. ${ }^{\circ}$ 4879/2020-CR., (2020) http://www.leyes.congreso.gob.pe/Documentos/2016_2021/Oficios/Congresistas/ OFICIO-005-2020-2021-OPSL-CR.pdf

Ordenanza que declara los días 28 y 29 de marzo de cada año, a nivel regional, como días de ayuno y oración por la salud de la población tumbesina. Ordenanza N. ${ }^{\circ} 005-$ 2020/GOB.REG.TUMBES-CR-CD, (2020), Diario Oficial El Peruano.

SCC. Exp. N. ${ }^{\circ}$ T-824803. (2004).

STC. Exp. N. ${ }^{\circ} 3283-2003-A A / T C . ~(2004)$.

STC. Exp. N. ${ }^{\circ}$ 05680-2009-PA/TC. (2010).

STC. Exp. N. ${ }^{\circ}$ 06111-2009-PA/TC. (2011). 